\title{
EU agricultural policy still not green
}

To the Editor - Agriculture is one of the key drivers of land-use change and species loss (worldwide, approximately half of the ice-free land surface is devoted to crop and livestock production ${ }^{1}$ ). Improving the link between agricultural policies and nature conservation, supporting sustainable farming systems benefiting nature conservation and rural people, should be a priority. This is a must if we are truly committed to achieving the objectives of international conservation agreements, such as the Aichi Biodiversity Targets 3 (removal or reformation of harmful incentives to biodiversity) and 7 (sustainable food and forestry production) $)^{2}$. The

Common Agricultural Policy (CAP) is one of the most important and expensive European sectoral policies (a budget of $€ 362.8$ billion in the period 2014-2020). The CAP has not escaped scrutiny, from both a socioeconomic and environmental point of view ${ }^{3,4}$, with an increasing breadth of actors calling for a true greening transformation of this policy ${ }^{4}$. This is particularly relevant in light of the ongoing reform of the CAP to shape its course after 2020 (the next CAP period 2021-2027).

After the World Trade Organization (WTO) Doha Round in 2001, and following the CAP Fischler reform in 2003, CAP Direct Payment aids were decoupled from production in order to reduce distortionary agricultural support ${ }^{5}$, boosting a debate that has been dominated by how to better allocate aids. Subsidizing any surface or producer will not maximize the benefits of this agricultural policy for European citizens, and fairer criteria to allocate aids are needed. Nowadays, $80 \%$ of the direct payments (approximately $€ 33$ billion per year) are concentrated in less than $20 \%$ of the potential beneficiaries ${ }^{6}$. Moreover, while direct payments are partially conditioned to farmers' compliance with basic rules for the environment, food safety, animal health and welfare, as well as good agricultural and environmental conditions, infringement levels are estimated to be remarkably high (about 30\%) ${ }^{7}$. The CAP's performance indicators do not take into account noncompliance; therefore, it is difficult to conclude whether the allocation of CAP aids is in accordance with the 'public money for public goods' principle. Remarkably, a considerable number of CAP social and environmental indicators have not improved since the past CAP period 2007-2013 .

Following the ongoing debate on whether the CAP post-2020 is taking the right reform lane $e^{8}$, now is the right time to

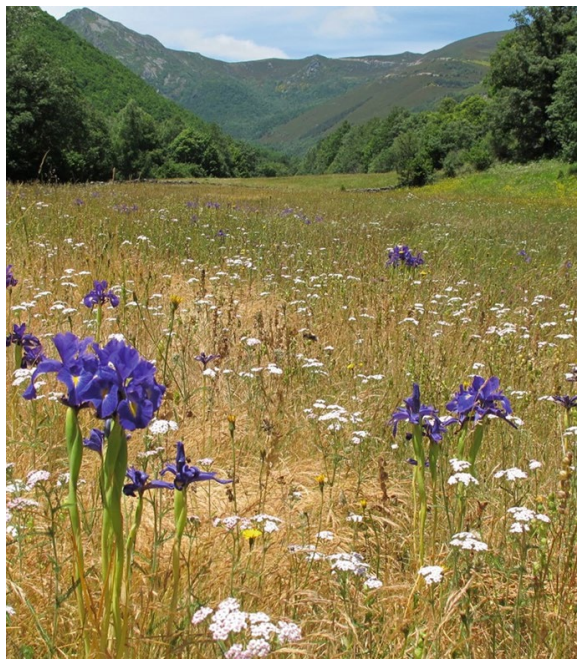

High Nature Value farmland in Ancares Mountains, Spain. Credit: image courtesy of Roberto J. Hermida

call for the implementation of allocation rules based on sustainability criteria benefiting farmers that truly need support and provide public goods, as well as for the use of reliable performance indicators. Accordingly, farms providing more public goods and services, linked to climate action and other environmental objectives ${ }^{9}$, should be prioritized. In Europe, the farms showing the highest environmental and biodiversity metrics are known as High Nature Value farmlands (HNVf), which are also valuable in terms of cultural heritage ${ }^{10}$. They have been integrated within the CAP structure, obtained some support through the European Agricultural Fund for Rural Development, and listed as a CAP indicator. However, their preservation has not been operationalized in practice yet ${ }^{11}$, receiving marginal prioritization and no targeted funding ${ }^{12}$. Consequently, HNVf have been degrading in quality and declining in extent throughout the European Union (EU) ${ }^{10}$. Potential frameworks are available for an effective HNVf delineation ${ }^{11}$, and under the agricultural-related WTO rules it is possible to subsidize HNVf preservation costs ${ }^{13}$.

An effective prioritization of farms in line with the CAP environmental objectives would reflect a true ambition to achieve not only the CAP's new objectives, but also international conservation and sustainability agreements $^{4,8}$. Surprisingly, the current regulatory proposal for the CAP in 2021$2027^{14}$ has not expanded the support for any specific form of sustainable agriculture, and even removed HNVf. This movement shows little environmental ambition and illustrates a lack of political will to address sustainability challenges ${ }^{4}$. Since European citizens have expressed concerns about how the current CAP is addressing sustainability challenges ${ }^{15}$, and considering the 'business as usual' structure of the proposed CAP reform ${ }^{4,8}$, without taking the three main challenges for the CAP seriously: sustainability, environment and climate change, and a balanced territorial development approach, such as in the case of removing HNVf in the European Commission's proposal for the CAP post-2020, we are weakening and delegitimizing this agricultural policy and the EU institutions before citizens.

\section{Alberto Navarro ${ }^{1}$ and \\ José Vicente López-Bao (DD)2* \\ ${ }^{1}$ Unaffiliated: A. Navarro. ${ }^{2}$ Research Unit in Biodiversity, UO-CSIC-PA, Oviedo University, Mieres, Spain. \\ *e-mail: jv.lopezbao@gmail.com}

Published online: 4 November 2019 https://doi.org/10.1038/s41893-019-0424-x

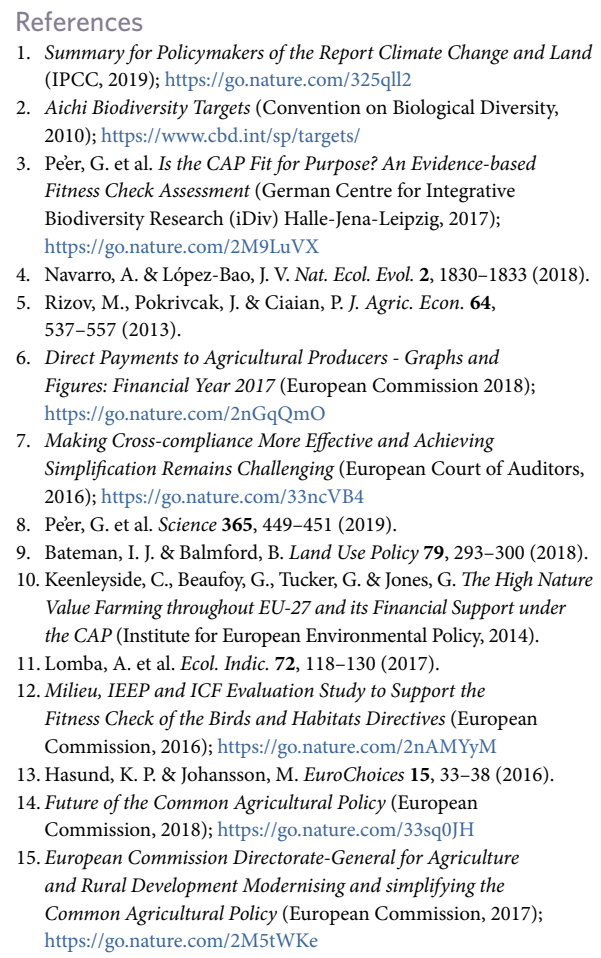
Economy, Industry and Competitiveness. 